\title{
Surgical repair of long-gap esophageal atresia: A retrospective study comparing the management of long-gap esophageal atresia in the Nordic countries
}

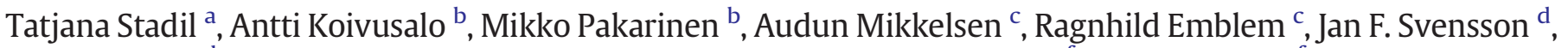 \\ Henrik Ehrén ${ }^{\mathrm{d}}$, Linus Jönsson ${ }^{\mathrm{e}}$, Jakob Bäckstrand ${ }^{\mathrm{e}}$, Helene Engstrand Lilja ${ }^{\mathrm{f}}$, Felipe Donoso ${ }^{\mathrm{f}}$, \\ Jørgen Mogens Thorup ${ }^{g}$, Thorstein Sæter ${ }^{\text {h }}$, Lars Rasmussen ${ }^{a}$, Rikke Neess Pedersen ${ }^{i}$, Pernilla Stenström ${ }^{j}$, \\ Einar Arnbjörnsson ${ }^{\mathrm{j}}$, Kristján Óskarsson ${ }^{\mathrm{k}}$, Niels Qvist ${ }^{\mathrm{a}, \mathrm{i}, \mathrm{l}, *}$ \\ a Surgical Department A, Odense University Hospital, Odense, Denmark \\ ${ }^{\mathrm{b}}$ Dept. of Pediatric Surgery, Children's Hospital, University of Helsinki, Helsinki, Finland \\ c Dept. of Gastric and Pediatric Surgery, Oslo University Hospital, Rikshospitalet and Ullevål, Oslo, Norway \\ d Department of Pediatric Surgery, Karolinska University Hospital and Department of Women's and Children's Health, Karolinska Institute, Stockholm, Sweden \\ e Department of Pediatric Surgery, Queen Silvia Children's Hospital, Gothenburg, Sweden \\ ${ }^{\mathrm{f}}$ Department of Pediatric Surgery, Children's Hospital and Department of Women's and Children's Health, Uppsala University, Uppsala, Sweden \\ ${ }^{g}$ Dept. of Pediatric Surgery, Rigshospitalet, Copenhagen University Hospital, Copenhagen, Denmark \\ ${ }^{\text {h }}$ Dept. of Pediatric Surgery, St. Olavs Hospital, Trondheim University Hospital, Trondheim, Norway \\ ${ }^{i}$ Hans Christian Andersen Children's Hospital, Odense University Hospital, Odense, Denmark \\ j Dept. of Pediatrics, Children's Hospital, Lund University, Lund, Sweden \\ k Children's Hospital, University Hospital, Reykjavik, Iceland \\ ${ }^{1}$ OPEN, Odense Patient data Explorative Network, Odense University Hospital, Odense, Denmark
}

\section{A R T I C L E I N F O}

\section{Article history:}

Received 2 February 2018

Received in revised form 3 July 2018

Accepted 31 July 2018

Available online $\mathrm{xxxx}$

\section{Key words:}

Esophageal atresia

Long gap

Gross type A

Gross type B

Surgical repair

Postoperative complication

\begin{abstract}
A B S T R A C T
Background: Several surgical procedures have been described in the reconstruction of long-gap esophageal atresia (LGEA). We reviewed the surgical methods used in children with LGEA in the Nordic countries over a 15 -year period and the postoperative complications within the first postoperative year.

Methods: Retrospective multicenter medical record review of all children born with Gross type A or B esophageal atresia between 01/01/2000 and 12/31/2014 reconstructed within their first year of life.

Results: We included 71 children; 56 had Gross type A and 15 type B LGEA. Delayed primary anastomosis (DPA) was performed in $52.1 \%$ and an esophageal replacement procedure in $47.9 \%$. Gastric pull-up (GPU) was the most frequent procedure (25.4\%). The frequency of chromosomal abnormalities, congenital heart defects and other anomalies was significantly higher in patients who had a replacement procedure. The frequency of gastroesophageal reflux (GER) was significantly higher after DPA compared to esophageal replacement $(p=0.013)$. At 1year follow-up the mean body weight was higher after DPA than after organ interposition $(p=0.043)$.

Conclusion: DPA and esophageal replacement procedures were equally applied. Postoperative complications and follow-up were similar except for the development of GER and the body weight at 1-year follow-up. Long-term results should be investigated.

Type of study: Treatment study.

Level of evidence: Level III.
\end{abstract}

(c) 2018 Elsevier Inc. All rights reserved.

\footnotetext{
is Declarations of interest: None.

* Corresponding author at: Surgical Department A, Odense University Hospital, Sdr. Boulevard 29, 5000, Odense C, Denmark. Tel.: + 4529694625 ; fax: + 4563203001. E-mail addresses: Tatjana.stadil@rsyd.dk (T. Stadil), Antti.Koivusalo@hus.fi (A. Koivusalo), Mikko.Pakarinen@hus.fi (M. Pakarinen), Audun.mikkelsen@medisin.uio.no (A. Mikkelsen), Remblem@ous-hf.no (R. Emblem), Jan.f.svensson@sll.se (J.F. Svensson), Henrik.ehren@karolinska.sll.se (H. Ehrén), Linus.jonsson@vgregion.se (L. Jönsson), Jakob.backstrand@vgregion.se (J. Bäckstrand), Helene.lilja@kbh.uu.se (H.E. Lilja), Felipe.donoso@kbh.uu.se (F. Donoso), Joergen.mogens.thorup@regionh.dk (J.M. Thorup), Thorstein.Seter@stolav.no (T. Sæter), Lars.Rasmussen@rsyd.dk (L. Rasmussen), Rikke.Neess.Pedersen@rsyd.dk (R.N. Pedersen), Pernilla.stenstrom@med.lu.se (P. Stenström), Einar.arnbjornsson@telia.com (E. Arnbjörnsson), Kristosk@landspitali.is (K. Óskarsson), Niels.qvist@rsyd.dk (N. Qvist).
} 
Long-gap esophageal atresia (LGEA) is a rare malformation that occurs in approximately $10 \%$ of children born with esophageal atresia (EA) [1] which has a prevalence of 1 in every 2500-4500 live births $[2,3]$. There is a lack of consensus on the method of surgical reconstruction in LGEA, where a primary esophageal anastomosis is impossible.

EA originates from a developmental disruption with abnormal separation of the embryonic foregut into the trachea and the esophagus, resulting in an upper and a lower esophageal pouch and in most cases in a tracheoesophageal fistula (TEF) [4,5]. However, the embryology is not completely understood and the etiology is unknown [4,5]. EA presents in different types and different classification systems have been described, the Gross classification being the most accepted [6]. EA is often associated with other major anomalies, a common one being the VACTERL/VATER association [7] consisting of vertebral, anal, cardiac, tracheal, esophageal, renal and limb anomalies.

The definition of LGEA is inconsistent varying from inability to obtain a primary anastomosis to a measured gap length of $\geq 2 \mathrm{~cm}$ or covering $\geq 2$ thoracic vertebras $[8,9]$.

To obtain esophagogastric continuity in patients with LGEA several surgical procedures have been developed and described. Overall, they include two principal techniques: 1) Delayed esophageal anastomosis [10-12] with or without prior elongation techniques as described by Foker et al. [13] and Kimura et al. [14] or 2) different esophageal replacement techniques such as interposition with jejunum [15] or colon [16], gastric pull-up (GPU) [15,17] or the reconstruction of a gastric tube $[18,19]$. Organ interposition or gastric pull-up can be retrosternal or posterior mediastinal [9].

The existing literature contains mainly institutional small patient series or case reports. Prospective comparative studies are lacking [20]. The objectives of the present study were to:

a) Review the surgical methods used in children born with LGEA Gross type A or B in the Nordic countries (Norway, Sweden, Finland, Iceland and Denmark) over a 15-year period.

b) Compare the frequencies of postoperative complications within one year associated with the different surgical methods.

We chose to omit the Type $C$ patients as the approach to surgical treatment may be very different owing to the existence of the tracheoesophageal fistula.

\section{Materials and methods}

Medical records on children born with esophageal atresia from January 1, 2000 to December 31, 2014 in the Nordic countries (Norway, Sweden, Finland, Iceland and Denmark) were reviewed to identify those with Gross type A or B LGEA. Inclusion required a preoperatively gasless abdomen on X-ray and reconstruction of the atresia within the first year of life.

The study was approved by the national Data Protection Agencies and health authorities according to the national requirements.

We collected data from a total of 10 institutions by retrospective medical record review. Each institution appointed one person who was responsible for the data collection and was authorized to enter the data into an electronic data collection form.

The collected data were facilitated and stored securely using the online system REDCap (Research Electronic Data Capture) [21] provided by the research infrastructure OPEN (Odense Patient data Explorative Network) hosted at the University of Southern Denmark.

The records of all children were searched for gestational age (GA), birth weight, birth length, the estimated gap length and the type of EA as well as other congenital anomalies. Exposure variables were the different surgical approaches; attempted primary anastomosis, delayed primary anastomosis (DPA), active elongation technique or esophageal replacement procedure (gastric pull-up, gastric tube, colonic interposition and jejunal interposition). Postoperative complications such as anastomotic leakage, anastomotic stricture and gastroesophageal reflux
(GER) as well as mortality composed the outcome variables. The definition of anastomotic leakage was emerging of luminal contents through the chest drain or leakage detected by imaging. Anastomotic stricture was defined as a narrowing of the esophageal lumen at the site of the anastomosis causing dysphagia and requiring dilatation, whereas a patient was considered to suffer from GER if there was a failure to thrive most reasonably owing to reflux or endoscopically proven inflammation with ulceration. Furthermore, we registered the body weight and length, total hospital stay, stay at intensive care unit, duration of parenteral nutrition and the total number of thoracotomies at 1-year followup as outcome variables.

\subsection{Statistical analysis}

Data were summarized and displayed by descriptive statistics. Relationships between categorical variables were examined by crosstabulations and presented as frequencies and percentages. Numerical, continuous variables were presented as means and standard deviations (SDs).

To test for differences and to control for potential outliers we used the $\chi^{2}$ test or the Fisher exact test for categorical, binary outcome variables and performed a logistic regression model to show the associations between these outcomes and the exposure variables. For the numerical variables, we used the Student's t-test to test for differences in means and linear regression was performed to describe the associations between the different treatments groups. Missing values were excluded from the analyses of outcome variables. A $p$-value $<0.05$ was considered statistically significant. Stata version 14.2 . was used for the statistical analyses.

\section{Results}

The total number of children born with EA in the Nordic countries in the study period was 978 . Of those we identified 80 patients with LGEA Gross type A or B of whom 75 met the inclusion criteria. Four patients were excluded owing to missing information. Of the 71 included patients 56 (78.9\%) presented with Gross type A and 15 (21.1\%) with Gross type B (Table 1). 34 patients were from Sweden, 16 from Norway, 13 from Finland, 1 from Iceland and 7 from Denmark. Patient characteristics, mode of delivery, associated anomalies and gap length are presented in Table 2. There was no significant difference in mean GA, mean birth weight and birth length in the two treatment groups, or in the mode of delivery. We found that chromosomal abnormalities, congenital heart defects and other anomalies were more common in patients who had an esophageal replacement procedure compared to those managed by DPA. The estimated gap length between the two esophageal pouches was about $1.1 \mathrm{~cm}$ longer in patients who received a replacement procedure compared to those who were managed by DPA ( $p=0.035)$. There was no significant difference in age at reconstruction between the two treatment groups (mean 124.2 days) (Table 2). Further analysis showed that DPA and GPU were performed in younger children compared to colonic interposition $(p=0.001$ and $p=0.002$ respectively). The children from Norway received DPA at a younger age compared to the children from Sweden and Finland $(p<0.001$ and $p=0.033$ respectively).

The type of surgical repair applied in the different countries is shown in Table 3.

\subsection{Surgical methods}

Regarding the definitive repair of LGEA 37 patients (52.1\%) received a DPA and in 34 patients (47.9\%) a replacement procedure was performed (Table 3). The most common replacement procedure was GPU (25.4\%); only in a few patients a gastric tube, colonic or jejunal interposition was performed. In 3 of the 18 patients managed by GPU a partial gastric pull-up procedure was performed. In Finland and Denmark most 
Table 1

Included patients from the different institutions born between January 1, 2000 and December 31, 2014.

\begin{tabular}{|c|c|c|c|c|}
\hline Patient characteristics & $\begin{array}{l}\text { Total } \\
(n=71)\end{array}$ & $\begin{array}{l}\text { Delayed primary anastomosis } \\
(n=37)\end{array}$ & $\begin{array}{l}\text { Esophageal replacement procedure } \\
(n=34)\end{array}$ & $p$-value \\
\hline $\begin{array}{r}\text { Gestational age } \\
\quad(\text { mean } \pm S D)\end{array}$ & $36.0 \pm 3.3$ & $36.6 \pm 3.2$ & $35.4 \pm 3.3$ & 0.123 \\
\hline $\begin{array}{l}\text { Birth weight }(\mathrm{g}) \\
\quad(\text { mean } \pm S D)\end{array}$ & $2458.0 \pm 688.7$ & $2588.2 \pm 673.7$ & $2316.4 \pm 686.6$ & 0.097 \\
\hline $\begin{array}{l}\text { Birth length }(\mathrm{cm}) \\
\quad(\text { mean } \pm S D)\end{array}$ & $\begin{array}{l}47.6 \pm 3.6 \\
(n=64)\end{array}$ & $\begin{array}{l}48.2 \pm 3.7 \\
(n=36)\end{array}$ & $\begin{array}{l}46.9 \pm 3.3 \\
(n=28)\end{array}$ & 0.140 \\
\hline \multicolumn{5}{|l|}{ Mode of delivery, $n(\%)$} \\
\hline C-section & $34(47.9 \%)$ & $16(43.2 \%)$ & $18(52.9 \%)$ & 0.414 \\
\hline Vaginal & $37(52.1 \%)$ & $21(56.8 \%)$ & $16(47.1 \%)$ & \\
\hline \multicolumn{5}{|l|}{ Other congenital anomalies, $n(\%)$} \\
\hline Chromosomal abnormality & $10(14.1 \%)$ & $2(5.4 \%)$ & $8(23.5 \%)$ & 0.041 \\
\hline Congenital heart defect ${ }^{\mathrm{a}}$ & $7(9.9 \%)$ & $1(2.7 \%)$ & $6(17.7 \%)$ & 0.049 \\
\hline Other anomalies ${ }^{\mathrm{b}}$ & $36(50.7 \%)$ & $14(37.8 \%)$ & $22(64,7 \%)$ & 0.024 \\
\hline None & $28(39.4 \%)$ & $21(56.8 \%)$ & $7(20.6 \%)$ & 0.002 \\
\hline $\begin{array}{l}\text { Estimated gap length }(\mathrm{cm}) \\
\quad(\text { mean } \pm S D)\end{array}$ & $\begin{array}{l}5.1 \pm 2.0 \\
(n=61)\end{array}$ & $\begin{array}{l}4.5 \pm 1.5 \\
(n=33)\end{array}$ & $\begin{array}{l}5.6 \pm 2.4 \\
(n=28)\end{array}$ & 0.035 \\
\hline $\begin{array}{l}\text { Age at definitive reconstruction (days) } \\
\quad(\text { mean } \pm S D)\end{array}$ & $124.2 \pm 83.9$ & $124.1 \pm 66.9$ & $124.3 \pm 100.3$ & 0.993 \\
\hline
\end{tabular}

Abbreviations: EA, esophageal atresia; LGEA, long-gap esophageal atresia.

a During the study period there were a total of 252 live born children with esophageal atresia in Finland: 116 in Helsinki, 31 in Oulu, 25 in Kuopio, 30 in Turku and 50 in Tampere.

b All cases of LGEA were either born in Helsinki or referred to the Children's Hospital in Helsinki for surgical treatment.

patients received an esophageal replacement procedure, whereas DPA was the most common procedure in Norway. In Sweden, the same fraction of patients had either a DPA or a replacement procedure. The one patient from Iceland was managed by DPA.

\subsection{Postoperative course}

Since there were too few patients in the 4 different groups of esophageal replacement techniques (Table 3 ) we combined these groups into one group for comparison with the group of patients who had a DPA.

All outcomes depicting the postoperative course are shown in Table 4. The frequency of postoperative complications was high and irrespective of the surgical method. The most common complications in both treatment groups (DPA or replacement procedure) were anastomotic stricture and GER; the latter occurred more often after DPA compared to a replacement procedure ( $p=0.013$ ). There were no significant differences in the frequency of anastomotic leakage, stricture and dilatation procedures between the two treatment groups, or in any of the other postoperative outcome parameters except the weight at 1-year follow-up. At one year of age the patients who were managed by DPA had a mean weight that was $768 \mathrm{~g}$ higher than patients who had an esophageal replacement procedure $(p=0.043)$.

Regression analysis showed a significant difference in the risk of GER that was lower after GPU compared to DPA $(p=0.020)$. Compared to DPA, patients needed fewer dilatation procedures after gastric tube formation ( $p=0.037$ ) and had a decreased weight gain at 1-year followup $(p=0.009)$ as well as a decreased growth in length at 1-year follow-up after GPU $(p=0.014)$. No other significant differences were found.

Adjustment for potential confounding factors such as gestational age and other congenital anomalies was conducted and did not result in any significant interactions.

\section{Discussion}

Our study showed an equal distribution between DPA and esophageal replacement in the reconstruction of LGEA. The choice was mainly based on the discretion of the surgeon and the most common

Table 2

Patient characteristics in the two different treatment groups.

\begin{tabular}{|c|c|c|c|c|}
\hline Patient characteristics & $\begin{array}{l}\text { Total } \\
(n=71)\end{array}$ & $\begin{array}{l}\text { Delayed primary anastomosis } \\
(n=37)\end{array}$ & $\begin{array}{l}\text { Esophageal replacement procedure } \\
(n=34)\end{array}$ & $p$-value \\
\hline $\begin{array}{l}\text { Gestational age } \\
(\text { mean } \pm S D)\end{array}$ & $36.0 \pm 3.3$ & $36.6 \pm 3.2$ & $35.4 \pm 3.3$ & 0.123 \\
\hline $\begin{array}{l}\text { Birth weight }(\mathrm{g}) \\
\quad(\text { mean } \pm S D)\end{array}$ & $2458.0 \pm 688.7$ & $2588.2 \pm 673.7$ & $2316.4 \pm 686.6$ & 0.097 \\
\hline $\begin{array}{l}\text { Birth length }(\mathrm{cm}) \\
\quad(\text { mean } \pm S D)\end{array}$ & $\begin{array}{l}47.6 \pm 3.6 \\
(n=64)\end{array}$ & $\begin{array}{l}48.2 \pm 3.7 \\
(n=36)\end{array}$ & $\begin{array}{l}46.9 \pm 3.3 \\
(n=28)\end{array}$ & 0.140 \\
\hline \multicolumn{5}{|l|}{ Mode of delivery, $n(\%)$} \\
\hline C-section & $34(47.9 \%)$ & $16(43.2 \%)$ & $18(52.9 \%)$ & 0.414 \\
\hline Vaginal & $37(52.1 \%)$ & $21(56.8 \%)$ & $16(47.1 \%)$ & \\
\hline \multicolumn{5}{|l|}{ Other congenital anomalies, $n$ (\%) } \\
\hline Chromosomal abnormality & $10(14.1 \%)$ & $2(5.4 \%)$ & $8(23.5 \%)$ & 0.041 \\
\hline Congenital heart defect ${ }^{\mathrm{a}}$ & 7 (9.9\%) & $1(2.7 \%)$ & $6(17.7 \%)$ & 0.049 \\
\hline Other anomalies ${ }^{\mathrm{b}}$ & $36(50.7 \%)$ & $14(37.8 \%)$ & $22(64,7 \%)$ & 0.024 \\
\hline None & $28(39.4 \%)$ & $21(56.8 \%)$ & $7(20.6 \%)$ & 0.002 \\
\hline $\begin{array}{l}\text { Estimated gap length }(\mathrm{cm}) \\
\quad(\text { mean } \pm S D)\end{array}$ & $\begin{array}{l}5.1 \pm 2.0 \\
(n=61)\end{array}$ & $\begin{array}{l}4.5 \pm 1.5 \\
(n=33)\end{array}$ & $\begin{array}{l}5.6 \pm 2.4 \\
(n=28)\end{array}$ & 0.035 \\
\hline $\begin{array}{l}\text { Age at definitive reconstruction (days) } \\
\quad(\text { mean } \pm S D)\end{array}$ & $124.2 \pm 83.9$ & $124.1 \pm 66.9$ & $124.3 \pm 100.3$ & 0.993 \\
\hline
\end{tabular}

a Requiring medical or surgical treatment (Spitz classification) [34].

b Other anomalies were mainly anal and duodenal atresia, kidney anomalies, VSD and ASD and vertebral anomalies. 
Table 3

Overview of the surgical methods used in the Nordic countries.

\begin{tabular}{|c|c|c|c|c|c|c|}
\hline Surgical methods ${ }^{\mathrm{a}}$ & $\begin{array}{l}\text { Total } \\
(n=71)\end{array}$ & $\begin{array}{l}\text { Norway } \\
(n=16)\end{array}$ & $\begin{array}{l}\text { Sweden } \\
(n=34)\end{array}$ & $\begin{array}{l}\text { Finland } \\
(n=13)\end{array}$ & $\begin{array}{l}\text { Iceland } \\
(n=1)\end{array}$ & $\begin{array}{l}\text { Denmark } \\
(n=7)\end{array}$ \\
\hline Attempted primary anastomosis & $\begin{array}{l}8 \\
(11.3 \%)\end{array}$ & 0 & $\begin{array}{l}3 \\
(8.8 \%)\end{array}$ & $\begin{array}{l}1 \\
(7.7 \%)\end{array}$ & 0 & $\begin{array}{l}4 \\
(57.1 \%)\end{array}$ \\
\hline Active elongation technique ${ }^{\mathrm{b}}$ & 6 & $\begin{array}{l}1 \\
(6.3 \%)\end{array}$ & $\begin{array}{l}2 \\
(8.3 \%)\end{array}$ & 0 & 0 & $\begin{array}{l}2 \\
(28.6 \%)\end{array}$ \\
\hline Delayed primary repair (DPA) & $37(52.1 \%)$ & $13(81.3 \%)$ & $17(50.0 \%)$ & $\begin{array}{l}5 \\
(38.5 \%)\end{array}$ & $\begin{array}{l}1 \\
(100 \%)\end{array}$ & $\begin{array}{l}1 \\
(14.3 \%)\end{array}$ \\
\hline Esophageal replacement procedure & $34(47.9 \%)$ & $\begin{array}{l}3 \\
(18.8 \%)\end{array}$ & $17(50.0 \%)$ & $\begin{array}{l}8 \\
(61.5 \%)\end{array}$ & 0 & $\begin{array}{l}6 \\
(85.7 \%)\end{array}$ \\
\hline Gastric pull-up ${ }^{c}$ & $\begin{array}{l}18 \\
(25.4 \%)\end{array}$ & $\begin{array}{l}1 \\
(6.3 \%)\end{array}$ & $\begin{array}{l}12 \\
(35.3 \%)\end{array}$ & 0 & 0 & $\begin{array}{l}5 \\
(71.4 \%)\end{array}$ \\
\hline Gastric tube & $\begin{array}{l}5 \\
(7.0 \%)\end{array}$ & 0 & $\begin{array}{l}3 \\
(8.8 \%)\end{array}$ & $\begin{array}{l}2 \\
(15.4 \%)\end{array}$ & 0 & 0 \\
\hline Colonic interposition & $\begin{array}{l}5 \\
(7.0 \%)\end{array}$ & $\begin{array}{l}2 \\
(12.5 \%)\end{array}$ & $\begin{array}{l}2 \\
(5.9 \%)\end{array}$ & 0 & 0 & $\begin{array}{l}1 \\
(14.3 \%)\end{array}$ \\
\hline Jejunal interposition & $\begin{array}{l}6 \\
(8.5 \%)\end{array}$ & 0 & 0 & $\begin{array}{l}6 \\
(46.2 \%)\end{array}$ & 0 & 0 \\
\hline
\end{tabular}

a Presented as frequencies (n) and percentages (\%).

b Dilation of upper and lower esophageal pouch $(n=2)$, Gough flap $(n=1)$, internal traction $(n=1)$, myotomy $(n=1)$ and ventricular curvature minor tube ( $n=1)$.

c 3 out of 18 patients had a partial gastric pull-up performed.

esophageal replacement procedure was GPU. Norway managed most children by DPA whereas Finland and Denmark mainly practiced replacement procedures. In Sweden an equal number of children were managed by DPA and replacement procedures. The one Icelandic patient was managed by DPA. As the only country, Finland preferred jejunal interposition as this method of reconstruction, in their experience, has a better adaption in patient growth and probably a better control of GER. The preferred choice for organ interposition in Denmark and Sweden was GPU.

The incidence of patients with LGEA Gross type A and B treated in the Nordic countries has been similar in the study period. According to the total population, the incidence of EA in Denmark was considerably less than seen in the other Nordic countries. The explanation for that is unknown and cannot be explained from differences in birth rates, which have been quite similar through the study period.
Most patient characteristics did not differ prominently, but other associated congenital anomalies were more common in patients who received a replacement procedure compared to those managed by DPA, reflecting that the challenges from the treatment of other associated anomalies may influence the planning of esophageal reconstruction. In cases where the child may have to undergo cardiac surgery during the neonatal period a simultaneous repair of the esophageal atresia might be more relevant than to wait for a DPA in selected cases. In our study, only one out of the seven patients with a congenital heart defect was managed by DPA, whereas the others received esophageal replacement.

Patients who received an esophageal replacement had a significantly longer gap between the two esophageal pouches than patients managed by DPA, which seems reasonable but the method of measurement

Table 4

Postoperative course after delayed primary repair and organ interposition.

\begin{tabular}{|c|c|c|c|c|}
\hline Postoperative outcome and 1-year follow-up & $\begin{array}{l}\text { Total } \\
(n=71)\end{array}$ & $\begin{array}{l}\mathrm{DPA} \\
(n=37)\end{array}$ & $\begin{array}{l}\text { Esophageal replacement procedure } \\
(n=34)\end{array}$ & $p$-value \\
\hline $\begin{array}{l}\text { Anastomotic leakage, } \\
n(\%)\end{array}$ & $25(35.2 \%)$ & $12(32.4 \%)$ & $13(38.2 \%)$ & 0.609 \\
\hline Anastomotic stricture, $n(\%)$ & $48(67.6 \%)$ & $23(62.2 \%)$ & $25(73.5 \%)$ & 0.307 \\
\hline $\begin{array}{l}\text { Number of dilatation procedures }{ }^{\mathrm{a}} \text {, } \\
\text { mean } \pm S D\end{array}$ & $\begin{array}{l}10.7 \pm 6.0 \\
(n=48)\end{array}$ & $\begin{array}{l}11.9 \pm 6.2 \\
(n=23)\end{array}$ & $\begin{array}{l}9.6 \pm 5.8 \\
(n=25)\end{array}$ & 0.189 \\
\hline GER, $n(\%)$ & $38(53.5 \%)$ & $25(67.6 \%)$ & $13(38.2 \%)$ & 0.013 \\
\hline $\begin{array}{l}\text { Other complications }{ }^{\mathrm{b}} \text {, } \\
n(\%)\end{array}$ & $11(15.5 \%)$ & $5(13.5 \%)$ & $6(17.7 \%)$ & 0.631 \\
\hline Reoperation $^{\mathrm{c}}, n(\%)$ & $8(11.3 \%)$ & $4(10.8 \%)$ & $4(11.8 \%)$ & 1.000 \\
\hline $\begin{array}{l}\text { Fundoplication }{ }^{\mathrm{d}} \text {, } \\
n(\%)\end{array}$ & $12(16.9 \%)$ & $10(27.0 \%)$ & $2(5.9 \%)$ & 0.158 \\
\hline $\begin{array}{l}\text { Total number of thoracotomies, } \\
\text { mean } \pm S D\end{array}$ & $1.2 \pm 0.5$ & $1.3 \pm 0.6$ & $1.2 \pm 0.5$ & 0.609 \\
\hline Total hospital stay (days), mean $\pm S D$ & $149.3 \pm 86.6$ & $151.6 \pm 75.8$ & $146.8 \pm 98.2$ & 0.817 \\
\hline $\begin{array}{l}\text { Total stay at ICU (days), } \\
\text { mean } \pm S D\end{array}$ & $\begin{array}{l}25.6 \pm 31.5 \\
(n=66)\end{array}$ & $\begin{array}{l}28.6 \pm 38.3 \\
(n=36)\end{array}$ & $\begin{array}{l}21.9 \pm 20.7 \\
(n=30)\end{array}$ & 0.391 \\
\hline $\begin{array}{l}\text { Duration of parenteral nutrition (days), } \\
\text { mean } \pm S D\end{array}$ & $24.4 \pm 30.4$ & $20.2 \pm 26.1$ & $28.9 \pm 34.3$ & 0.230 \\
\hline $\begin{array}{l}\text { Weight at 1-year follow-up (g), } \\
\text { mean } \pm S D\end{array}$ & $\begin{array}{l}8684.9 \pm 1568.9 \\
(n=68)\end{array}$ & $\begin{array}{l}9046.3 \pm 1436.2 \\
(n=36)\end{array}$ & $\begin{array}{l}8278.3 \pm 1633.6 \\
(n=32)\end{array}$ & 0.043 \\
\hline $\begin{array}{l}\text { Length at 1-year follow-up }(\mathrm{cm}) \text {, } \\
\text { mean } \pm S D\end{array}$ & $\begin{array}{l}73.7 \pm 5.2 \\
(n=53)\end{array}$ & $\begin{array}{l}74.8 \pm 4.7 \\
(n=27)\end{array}$ & $\begin{array}{l}72.5 \pm 5.5 \\
(n=26)\end{array}$ & 0.107 \\
\hline Postoperative mortality, $n(\%)$ & $1(1.4 \%)$ & 0 & $1(2.9 \%)^{\mathrm{e}}$ & 0.479 \\
\hline
\end{tabular}

Abbreviations: DPA, delayed primary anastomosis; GER, gastroesophageal reflux; ICU, intensive care unit; SD, standard deviation.

a Dilatation owing to anastomotic stricture.

b Other complications were mainly pneumothorax, pneumonia and sepsis.

c Reoperation owing to anastomotic leakage.

d Nissen fundoplication owing to GER.

e This patient died 7 days after jejunal interposition. 
has not been defined properly prior to data collection, which makes this variable problematic.

Norway performed DPA in significantly younger children compared to Sweden and Finland, which may result in poorer growth of the esophageal pouches and more tension on the anastomoses, but the clinical significance is unknown.

A relative high frequency of Cesarean section was found. The reason is unknown but could partly be explained by prenatal diagnosing or, speculating, that the deliveries might have been complicated because of polyhydramnios owing to the atresia. The reasons for not including information on prenatally diagnoses of the atresia were great differences in the utility of prenatal ultrasonography between the different counties and with significant changes over time. For further and reliable information on the indication for Cesarian section it would have been necessary to access the mothers' records, and for that we had no approval from the authorities.

Postoperative complications within the first postoperative year were common and similar in both treatment groups except for GER being more frequent after DPA. Despite the choice of treatment, the total hospital stay in the first year of life was considerably long which poses a great economic burden in healthcare. All children were treated at a regional pediatric surgical center as recommended given the rarity of this condition [22].

Our results confirm that there is no gold standard in the surgical treatment of LGEA [1]. A recent survey of European pediatric surgeons [23] showed that the preferred management for LGEA Gross type A was DPA and in cases where esophageal replacement was needed GPU was the preferred procedure. This is also in accordance to a review by Von Allmen and Wijnen [8] who showed that DPA is the preferred method and that GPU is favored for esophageal replacement. This is somewhat different from the results in our study. The reason could be that in only 6 patients an active elongation technique had been applied. Owing to the relatively few cases, eventual changes in treatment modality during the investigation period could not be assessed. The importance of an explicit definition of LGEA is reflected in the lack of an ideal surgical method for reconstruction and together with the few numbers of patients per institution this may impair surgical experience and evidence in the field [1]. Several publications also include Gross type $C$ patients, which make the definition of LGEA more inconsistent. Our definition of LGEA was confined to Gross type A and B to obtain a homogeneous group of patients.

A high rate of postoperative complications was registered after both DPA and esophageal replacement procedure. Anastomotic leakage occurred in $32.4 \%$ of patients after DPA and in $38.2 \%$ after replacement procedure. Our incidence of leakage after DPA was similar to the $28.7 \%$ reported in a meta-analysis investigating the complications and longterm outcome in patients with LGEA managed by DPA [12]. A considerably higher leakage rate of $58 \%$ has been reported by Zani et al. [24] presumably owing to routine postoperative esophagrams that were performed after esophageal repair facilitating the diagnosis of small, clinically insignificant leaks. Routine postoperative esophagrams were performed in most of the children we included. One possible reason for the low frequency of leakage we found could be a nonstandardized investigation protocol. Most leaks resolve spontaneously [11,12] without the need for surgery, which is indicated by our low frequency of reoperation in both treatment groups. Anastomotic stricture is another typical postoperative complication and occurred in $62.6 \%$ of children managed by DPA and $73.5 \%$ of children who received an esophageal replacement procedure. Data on the number of dilatation procedures within the first postoperative year were available for only 48 of the children included in this study and a mean of 10.7 procedures was recorded. Friedmacher and Puri [12] reported a stricture rate of 57.0\% after DPA similar to Zani et al. [24] who reported a rate of $58.0 \%$. The incidence of symptomatic GER in Friedmacher and Puri's [12] meta-analysis was $47.8 \%$. In our study, we found a $53.5 \%$ incidence of GER. This was even higher in the study from Zani et al. [24] with a 75\% incidence. According to Friedmacher and Puri [12] the development of GER after DPA required a more aggressive treatment compared to other reconstruction methods. Thus, up to $30 \%$ of the patients had antireflux surgery within the first postoperative year owing to symptomatic reflux or recurrent stricture. This is in accordance with our study, where $27.0 \%$ had a fundoplication performed after DPA compared to only 5.9\% after an interposition procedure. In addition, the frequency of GER and stricture after DPA was similarly high in our study emphasizing the association between symptomatic reflux and recurrent stricture as found by Friedmacher and Puri [12]. Compared to DPA the frequency of GER after GPU was significantly lower in our study. GER is often associated with mobilization of the distal esophagus and esophageal anastomosis under tension, displacing the gastroesophageal junction upward $[11,12,25]$, which is why the higher risk for GER after DPA seems reasonable. GPU may also require notably dissection and transposition of the distal esophageal segment with loss of the angle of His [26], facilitating GER. However, in a series of infants with LGEA, GPU did not result in any major reflux problems [27]. Furthermore, high risk of early GER is a known disadvantage of GPU $[27,28]$. One reason for the different incidences could lie in the definition of GER. Our definition of GER was failure to thrive owing to reflux symptoms, endoscopically proven inflammation and/or ulceration. Other studies relied on radiologically proven GER $[24,29]$. Thus, the interpretation on GER should be taken with great caution, both in our study and in others. GER may be difficult to diagnose and evaluate in patients with e.g. GPU and several studies include patients with LGEA Gross type $C$ which poses a less complex condition than type A [1].

Albeit the general understanding that one disadvantage of DPA is prolonged hospital stay owing to waiting for the esophageal segments to grow, we found no significant difference in the total hospital stay between the two treatment groups. Several not well-defined factors may influence the timing of DPA, but it is surprising that the hospital stay was similar in both groups. The reason might be that in case of delayed surgery some of the babies may be discharged from the hospital to a home care system. The advantages of earlier repair are the avoidance of permanent suction on the upper pouch, which may be troublesome with the risk of aspiration pneumonia, and imposes the possibility of early oral feeding. The disadvantages may be the necessity of organ interposition.

At 1-year follow-up the patients who were managed by DPA had gained more weight compared to patients who received esophageal replacement. This seems reasonable owing to the, although not significant, somewhat longer duration of parenteral nutrition after replacement procedure and the higher frequency of associated anomalies in the patients who had an esophageal replacement.

Only one patient died postoperatively after jejunal interposition. The low mortality rate can be attributed to the continuous advances in pediatric surgery and anesthesia, neonatal intensive care and parenteral nutrition, which have improved the survival rate of children with EA to approximately 95\% [12]. All cases with a diagnosis of esophageal atresia that were admitted to the centers were included, but there could be some cases born with the malformation that never reached one of the centers. Thus, some kind of selection could have occurred. Based on calculation of the average birthrate and population in the Nordic countries within the study period the incidence of esophageal atresia was approximately 1:4400 and comparable to the literature.

Only few patients had colonic or jejunal interposition or a gastric tube formation which make it impossible to compare these approaches to DPA and GPU. Regression analyses did not reveal any significant associations between these procedures and the frequency of leakage, stricture and GER compared to DPA.

We focused on the complications within the first postoperative year but the surgical repair of EA may lead to long-term complications such as persistent GER symptoms, dysphagia and respiratory problems [30,31]. Thus, to identify the most favorable surgical treatment for children with LGEA it is necessary to appraise both the short-term and long-term postoperative course. 
Many barriers such as the rarity of the condition, lacking consensus on the definition of LGEA and missing treatment guidelines impede the research in this field. The continuous development of new surgical modifications and techniques such as intramural injection of botulinum toxin type A to facilitate end-to-end anastomosis [32] and magnetic compression anastomosis [33] challenges the task of finding the best treatment option. One of the most recent developments is tissue engineering of functional esophageal grafts in which vascularization and innervation still constitute a hurdle [8]. The Federation of Esophageal Atresia and Tracheo-Esophageal Fistula support groups (EAT), led by patients and their parents, attempt to share knowledge, experience and resources by facilitating projects as the European Reference Network of Rare Inherited and Congenital Anomalies (ERNICA) [31] with the goal to develop guidelines regarding the definition and management of LGEA. The present study may be an important input to these discussions. Final conclusions may not be drawn until the longterm results have been investigated. The International Network of Esophageal Atresia (INoEA) [1] is a working group set up by health professionals and researchers to initiate consensus on guidelines on EA and collaborative research programs, which are lacking in the current literature. The importance of a clear definition of LGEA for instance has been assessed by this working group and has been published in their latest position paper [1].

\subsection{Methodological considerations}

The Nordic countries have comparable health-care systems and are therefore suitable for conducting multicenter studies. To our knowledge, the present series is the largest among the published literature on Gross type A and B esophageal atresia.

The main limitation of this study is its retrospective design with the struggle of incomplete documentation. Some data were lacking or difficult to identify. Owing to errors in the registration of the disease it is possible that we failed to identify few eligible patients. This emphasizes the need for international registries of standardized follow-up data which would facilitate prospective research in this area. Another weakness is that the GPU treatment group consists of patients that either had a partial or a total gastric pull-up and these procedures are essentially not comparable.

The considerably long study period of 15 years could also have influenced our results, owing to continuous advances in surgery, pediatric anesthesia and neonatal intensive care [12]. We were not able to analyze possible confounders as the number of surgeons, their experiences and clinical judgments.

Furthermore, it couldn't be considered that the patients come from different countries and were operated by different surgeons. This however resembles a real-life situation.

\section{Conclusion}

There was a prominent diversity in the surgical approach of LGEA Gross type A and B and apart from the occurrence of GER we were not able to demonstrate signifying differences in the postoperative outcome of the various surgical treatments. Further multicenter studies with a prospective design, large patient population and longer follow-up period are recommended to assess the best surgical approach.

\section{Funding sources}

This study was supported by the University of Southern DenmarkFaculty of Health and Science; Surgical Department A, Odense University Hospital; the Research Foundation of Odense University Hospital, Denmark; NordForsk-part of the Nordic and international research cooperation; The Crown Princess Lovisa Foundation and Sällskapet Barnavård.

\section{References}

[1] van der Zee DC, Bagolan P, Faure C, et al. Position paper of INoEA working group on long-gap esophageal atresia: for better care. Front Pediatr 2017;5:63.

[2] Depaepe A, Dolk H, Lechat MF. The epidemiology of tracheo-oesophageal fistula and oesophageal atresia in Europe. EUROCAT working group. Arch Dis Child 1993;68(6): $743-8$.

[3] Pedersen RN, Calzolari E, Husby S, et al. Oesophageal atresia: prevalence, prenatal diagnosis and associated anomalies in 23 European regions. Arch Dis Child 2012;97 (3):227-32.

[4] Genevieve D, de Pontual L, Amiel J, et al. Genetic factors in isolated and syndromic esophageal atresia. J Pediatr Gastroenterol Nutr 2011;52(Suppl. 1):S6-8.

[5] Smith N. Oesophageal atresia and tracheo-oesophageal fistula. Early Hum Dev 2014 90(12):947-50

[6] Gross ER. The surgery of infancy and childhood: its principles and techniques. W. B. Saunders: Philadelphia and London; 1953.

[7] Quan L, Smith DW. The VATER association: vertebral defects, anal atresia, T-E fistula with esophageal atresia, radial and renal dysplasia: a spectrum of associated defects. J Pediatr 1973;82(1):104-7.

[8] von Allmen D, Wijnen RM. Bridging the gap in the repair of long-gap esophageal atresia: still questions on diagnostics and treatment. Eur J Pediatr Surg 2015;25(4):312-7.

[9] Liu J, Yang Y, Zheng C, et al. Surgical outcomes of different approaches to esophageal replacement in long-gap esophageal atresia: a systematic review. Medicine 2017;96 (21):e6942.

[10] Puri P, Blake N, O'Donnell B, et al. Delayed primary anastomosis following spontaneous growth of esophageal segments in esophageal atresia. J Pediatr Surg 1981;16(2):180-3.

[11] Puri P, Khurana S. Delayed primary esophageal anastomosis for pure esophagea atresia. Semin Pediatr Surg 1998;7(2):126-9.

[12] Friedmacher F, Puri P. Delayed primary anastomosis for management of longgap esophageal atresia: a meta-analysis of complications and long-term outcome. Pediatr Surg Int 2012;28(9):899-906.

[13] Foker JE, Kendall Krosch TC, Catton K, et al. Long-gap esophageal atresia treated by growth induction: the biological potential and early follow-up results. Semin Pediatr Surg 2009;18(1):23-9.

[14] Kimura K, Nishijima E, Tsugawa C, et al. Multistaged extrathoracic esophageal elongation procedure for long gap esophageal atresia: experience with 12 patients. Pediatr Surg 2001;36(11):1725-7.

[15] Gallo G, Zwaveling S, Van der Zee DC, et al. A two-center comparative study of gastric pull-up and jejunal interposition for long gap esophageal atresia. J Pediatr Surg 2015;50(4):535-9.

[16] Hamza AF. Colonic replacement in cases of esophageal atresia. Semin Pediatr Surg 2009;18(1):40-3.

[17] Gupta DK, Sharma S, Arora MK, et al. Esophageal replacement in the neonatal period in infants with esophageal atresia and tracheoesophageal fistula. J Pediatr Surg 2007:42(9):1471-7.

[18] McCollum MO, Rangel SJ, Blair GK, et al. Primary reversed gastric tube reconstruction in long gap esophageal atresia. J Pediatr Surg 2003;38(6):957-62.

[19] Borgnon J, Tounian P, Auber F, et al. Esophageal replacement in children by an isoperistaltic gastric tube: a 12-year experience. Pediatr Surg Int 2004;20(11-12): 829-33.

[20] Gallo G, Zwaveling S, Groen H, et al. Long-gap esophageal atresia: a meta-analysis of jejunal interposition, colon interposition, and gastric pull-up. Eur J Pediatr Surg 2012;22(6):420-5.

[21] Harris Paul A, Taylor Robert, Thielke Robert, et al. Research electronic data capture (REDCap)-a metadata-driven methodology and workflow process for providing translational research informatics support. J Biomed Inform 2009;42(2):377-81.

[22] Spitz L. Oesophageal atresia treatment: a 21st-century perspective. J Pediatr Gastroenterol Nutr 2011;52(Suppl. 1):S12.

[23] Zani A, Eaton S, Hoellwarth ME, et al. International survey on the management of esophageal atresia. Eur J Pediatr Surg 2014;24(1):3-8.

[24] Zani A, Cobellis G, Wolinska J, et al. Preservation of native esophagus in infants with pure esophageal atresia has good long-term outcomes despite significant postoperative morbidity. Pediatr Surg Int 2016;32(2):113-7.

[25] Tovar JA, Fragoso AC. Anti-reflux surgery for patients with esophageal atresia. Dis Esophagus 2013;26(4):401-4.

[26] Reismann M, Granholm T, Ehren H. Partial gastric pull-up in the treatment of patients with long-gap esophageal atresia. World J Pediatr 2015;11(3):267-71.

[27] Spitz L. Gastric transposition via the mediastinal route for infants with longgap esophageal atresia. J Pediatr Surg 1984;19(2):149-54.

[28] Loukogeorgakis SP, Pierro A. Replacement surgery for esophageal atresia. Eur ] Pediatr Surg 2013;23(3):182-90.

[29] Thakkar HS, Cooney J, Kumar N, et al. Measured gap length and outcomes in oesophageal atresia. J Pediatr Surg 2014;49(9):1343-6.

[30] Pedersen RN, Markow S, Kruse-Andersen S, et al. Esophageal atresia: gastroesophageal functional follow-up in 5-15 year old children. J Pediatr Surg 2013;48(12):2487-95.

[31] Svoboda E, Fruithof J, Widenmann-Grolig A, et al. A patient led, international study of long term outcomes of esophageal atresia: EAT 1. J Pediatr Surg 2017;53(4): 610-5

[32] Ellebaek M, Qvist N, Rasmussen L. Secondary anastomosis after preoperative botulinum type a toxin injection in a case with long gap oesophageal atresia. Eur J Pediatr Surg 2013;23(4):325-6.

[33] Lovvorn HN, Baron CM, Danko ME, et al. Staged repair of esophageal atresia: pouch approximation and catheter-based magnetic anastomosis. J Pediatr Surg Case Rep 2014:2(4):170-5.

[34] Spitz L, Kiely EM, Morecroft JA, et al. Oesophageal atresia: at-risk groups for the 1990s. J Pediatr Surg 1994;29(6):723-5. 